\title{
Produksi Film Animasi 2D Pool
}

\author{
${ }^{1}$ Meidiana Safitri, ${ }^{2}$ Tanto Harthoko, ${ }^{3}$ Andri Nur Patrio \\ ${ }^{1}$ Program Studi D-3 Animasi Institut Seni Indonesia \\ animasi@isi.ac.id \\ ${ }^{2}$ Program Studi D-3 Animasi Institut Seni Indonesia \\ tantohjogja@gmail.com \\ ${ }^{3}$ Program Studi D-3 Animasi Institut Seni Indonesia \\ andrinurpatrio@gmail.com
}

\begin{abstract}
Abstrak
Film animasi ini berkisah tentang seorang anak bernama Boy yang sedang berusaha mengatasi traumanya terhadap kolam renang. Trauma merupakan dampak dari pengalaman mengerikan yang pernah terjadi semasa hidup. Dengan waktu pemulihan yang tidak sebentar, seorang penderita selalu terbayang-bayang kejadian buruk dan beberapa gejala traumatis yang sedikit sulit teratasi. Dengan begitu tokoh membutuhkan dukungan orang terdekat untuk sembuh secara perlahan. Penciptaan film animasi 2D "Pool" menggunakan teknik frame by frame langsung pada perangkat lunak pembuatan animasi. Semua proses pembuatan dari produksi sampai pascaproduksi menggunakan media digital dan menghasilkan film animasi berdurasi 2 menit.
\end{abstract}

Kata Kunci: Produksi; animasi 2D; Trauma; Kolam Renang; Anak-anak

\section{Production of Pool, a 2D Animation}

\section{Abstract}

The story of a boy named Boy who is trying to overcome his trauma to a swimming pool. Trauma is the result of a terrible experience that has occurred during life. With a long recovery time, a trauma sufferer always imagines bad events and some traumatic symptoms that is difficult to overcome. Therefore, the character needs the support of the closest people to recover slowly. The creation of $2 \mathrm{D}$ animated film "Pool" using direct frame by frame technique in animation creation software. All manufacturing processes fromproduction to postproduction use digital media and produce an animated film with duration of 2 minutes.

Keywords: Production; 2D Animations; Trauma; Swimming Pool; Children

\section{Pendahuluan}

Trauma berasal dari kata Yunani "tramatos" yang berati luka atau cedera yang bersumber dari luar diri. Trauma adalah suatu peristiwa atau situasi di mana seseorang dihadapkan dengan suatu peristiwa aktual yang dapat menyebabkan kematian atau cidera serius pada diri sendiri atau orang lain sehingga muncul perasaan diteror dan perasaan putus asa, peristiwa itu di luar kemampuan individu untuk bertahan, 
mengatasi, atau menghindar. Menurut Kaplan dan Sadock (1997), orang bisa dikatakan mempunyai trauma adalah mereka harus mengalami suatu stres emosional yang besar dan berlebih sehingga orang tersebut tidak bisa mengendalikan perasaan itu sendiri yang menyebabkan munculnya trauma pada hampir setiap orang.

Trauma dapat disebabkan dengan berbagai macam kejadian buruk setiap orang setidaknya pernah satu kali merasa stres dalam hidupnya, entah itu karena masalah rumah tangga, keuangan di akhir bulan, atau karena terjebak di tengah macetnya jalanan. Akan tetapi, tidak semua orang pernah mengalami stres akut. stres akut sangatlah berbeda dengan stres harian yang biasa dialami. Stres akut umumnya terjadi mengikuti sebuah peristiwa traumatik yang orang lain alami atau saksikan. Misalnya bencana alam, KDRT, kecelakaan lalu lintas, kekerasan seksual, hingga kembali dari perang. Dengan kata lain, pasien histeria dikuasai oleh pengalaman masa lalu yang disertai dengan kecemasan (Hall, 2000). Perkembangan animasi saat ini sangatlah pesat sesuai dengan kebutuhan penggunanya. animasi untuk kebutuhan iklan dengan kepentingan yang beragam sudah sangat cukup terpenuhi. Demikian juga kebutuhan animasi untuk kepentingan edukasi, hiburan, dan industri. Usaha animasi yang terkemas dalam bentuk wawasan yang menerapkan sudut pandang tokoh untuk memudahkan penonton dalam merasakan rasa empati terhadap penderita trauma sangatlah jarang.

Maka dari itu untuk film pendek animasi kali ini akan dikisahkan melalui sudut pandang seorang penderita yang telah mengalami kejadian trauma. Berbagai alasan digunakannya teknik dua dimensi salah satunya yaitu software yang lebih ringan saat digunakan di komputer dengan spesifikasi terbatas. Lalu, alasan selanjutnya dari animasi dua dimensi adalah efisiensi yang dapat dihasilkan. Animasi didefinisikan sebagai proses merekam dan memainkan kembali serangkaian gambar statis untuk mendapatkan sebuah ilusi pergerakan. Animasi sering diartikan sebagai "menghidupkan" dari suatu benda. mati atau benda statis yang kemudian bisa menciptakan gerak, atau kesan bergerak (Fernandez, 2002, hal. 128). Sebagai bentuk seni, animasi dua dimensi membutuhkan banyak keterampilan dan kreativitas untuk menghasilkan objek, karakter, dan dunia yang menarik bagi khalayak target dan secara akurat menyampaikan cerita dan pesan. Selain itu, banyak teknik dan gaya yang bias diterapkan. 
Judul "Pool" dipilih karena cerita terfokus kepada pengalaman tokoh yang mengalami kejadian truma di kolam renang dan dapat berdampak terpicunya flashback atau kejadian buruk lampau yang menyebabkan awal mula trauma tersebut hadir. Seorang yang telah mengalami kejadian traumatik sangat membutuhkan dukungan orang-orang terdekat dalam menghadapi gejala-gejala stres yang bermunculan. Dikarenakan tokoh hanya memiliki seorang ayah, maka di akhir cerita ayah tersebut akan memeluk tokoh utama untuk menyatakan sebuah dukungan emosional antara ayah dan anaknya.

\section{Pembahasan}

Konsep ide film animasi 2D "Pool" mengisahkan tentang seorang anak lakilaki bernama Boy yang berusaha menghadapi ketakutannya akan trauma terhadap kolam renang. Tetapi hal yang tidak terduga terjadi, ia terjatuh tenggelam di dalam kolam. Lalu saat tersadar ia melihat Papanya dalam keadaan basah. Ia menyadari bahwa ia tidak sendirian, dengan dukungan dan kasih sayang dari orang terdekat perlahan akan ada harapan.

Ide ini dikembangkan kembali melalui survei dengan meminta pendapat dan saran dari masyarakat sekitar penulis. Lalu informasi dicari melalui berbagai media untuk mendukung keberlangsungan cerita. Mulai dari dasar penyebab, dampak, dan penangannya. Lalu survei kolam renang dan lokasi yang sekiranya cocok dengan cerita yang akan dibawakan. Banyak masukan dan saran yang ada sehingga kisah animasi diberi judul "Pool", dan karakter utama anak laki-laki ini bernama Boy yang artinya anak lelaki. Boy dicirikan memiliki wajah yang kuyu dan badan yang kurus, serta rambut lurus berpotongan mangkuk. 


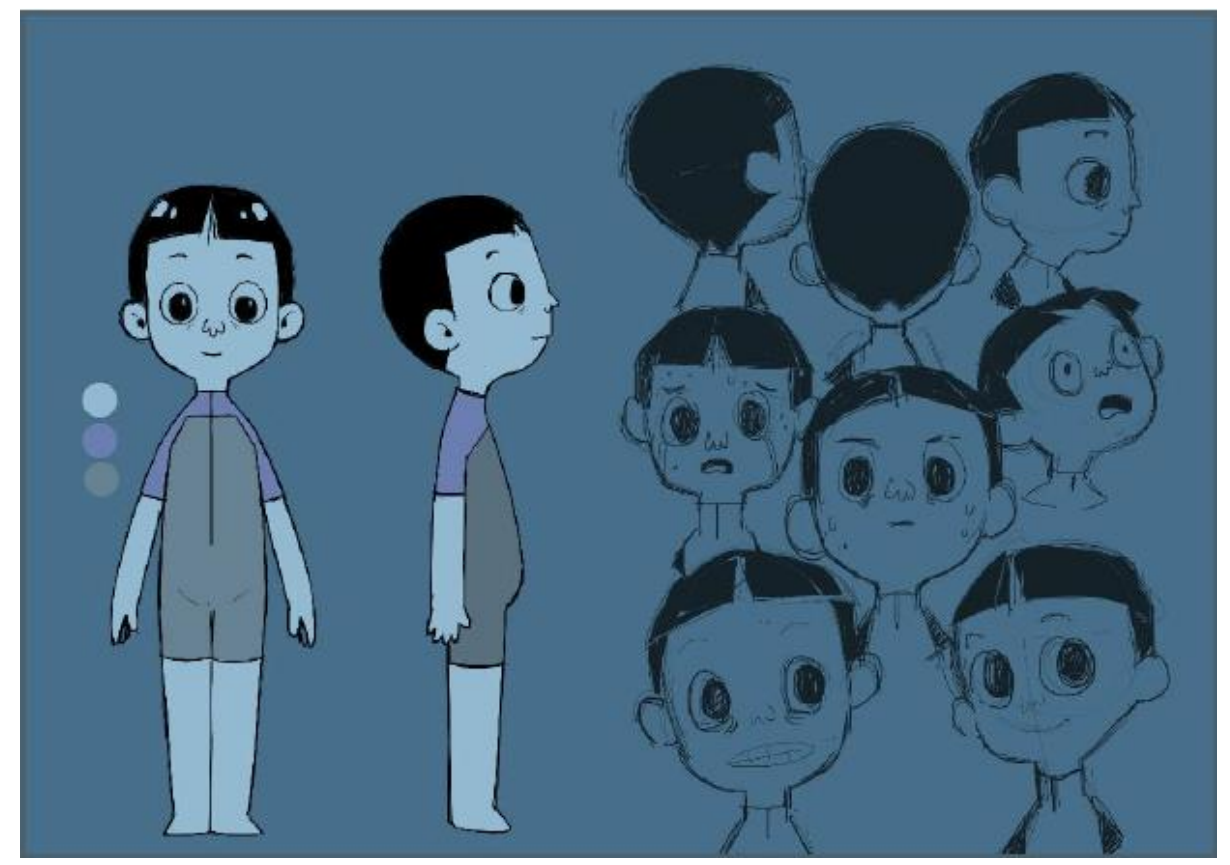

Gambar 1 rancangan karakter Boy

Karakter Boy dirancang memiliki wajah yang kuyu dan badan yang kurus serta rambut lurus potongan mangkuk dengan kulit berwarna putih. Pakaian renang yang merupakan seragam sekolah untuk praktek renang senantiasa hadir dengan perbedaan warna ungu dan abu-abu.

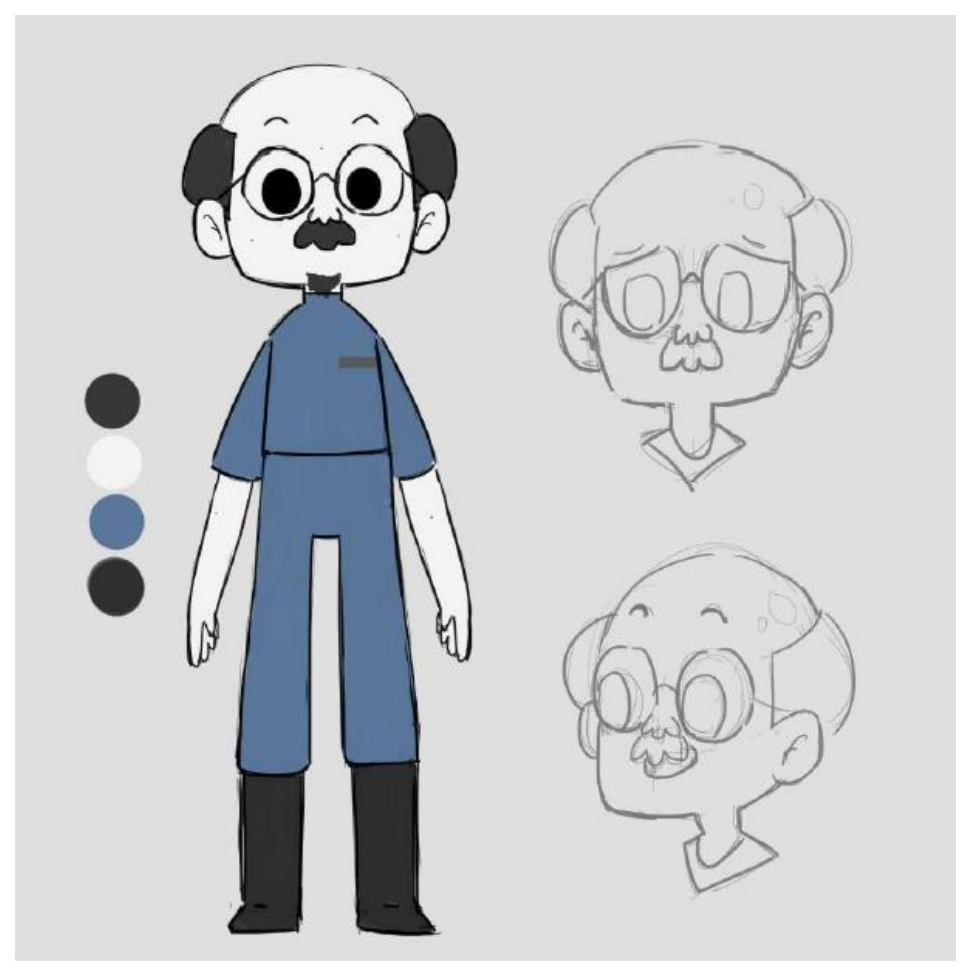

Gambar 2 rancangan karakter papa 
Karakter Papa dirancang dengan penampilan warna rambut keriting yang agak pekat dengan jenggot dan baju petugas kebersihannya yang khas.

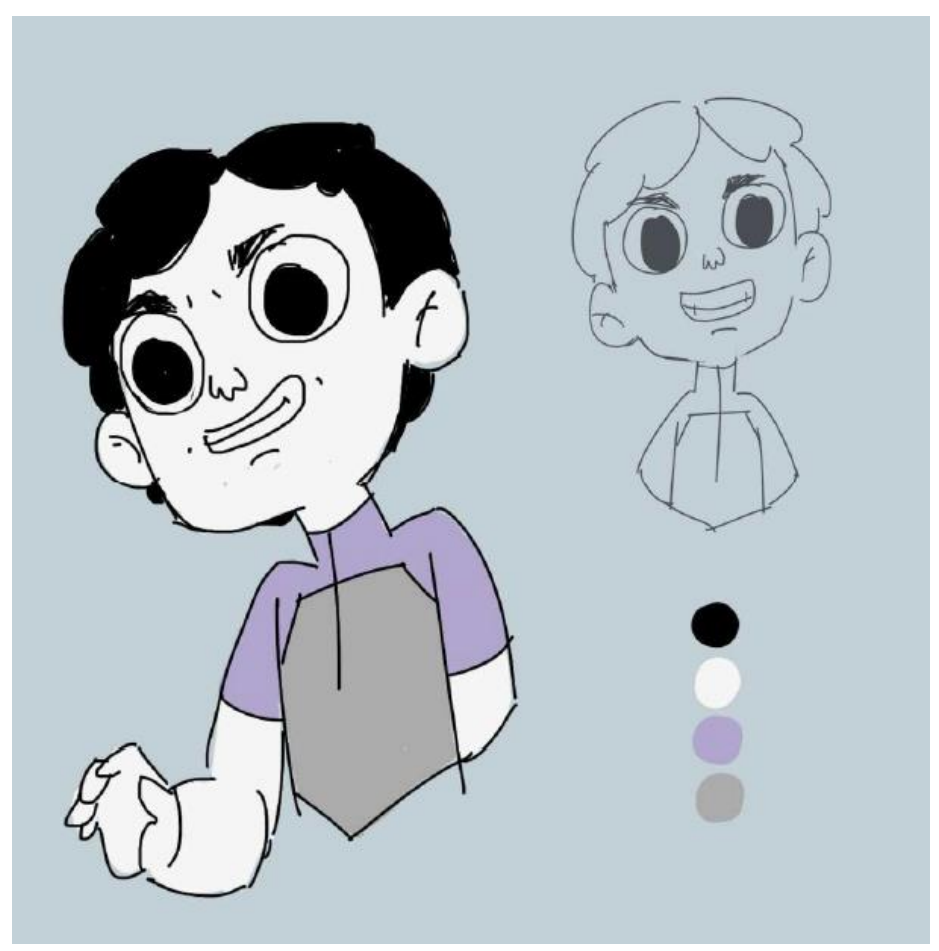

Gambar 3 rancangan karakter teman jahat

Tokoh teman jahat divisualisasikan dengan rambut ikal dan wajah yang jahil dan licik. Tokoh ini menggunakan seragam renang yang sama dengan Boy.

Dalam film "Pool," produksi dilakukan dengan pembuatan layout background dan berlanjut ke proses animating. Proses setelahnya adalah proses pembuatan background dengan color pallete yang sudah disiapkan. Dari background dan color pallette yang telah siap kemudian proses dilanjutkan dengan pembuatan keypose, inbetween dan clean up. Apabila satu shot sudah lolos seleksi quality control maka langsung masuk ke tahap coloring. Shot yang dikerjakan kurang lebih ada 32 shot. 


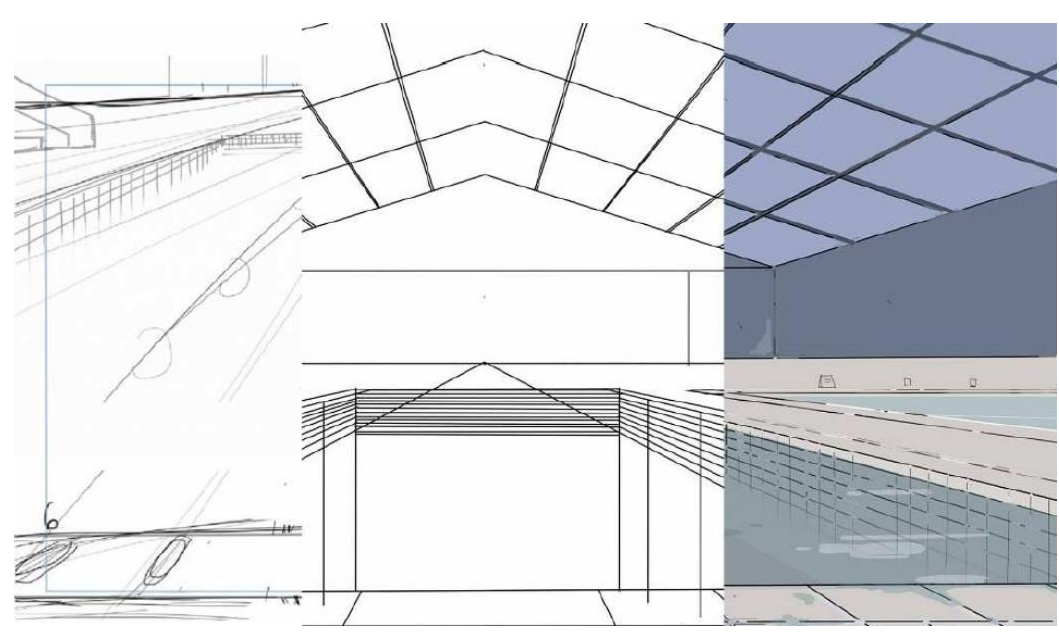

Gambar 4 Proses Perancangan Background "Pool"

Pada proses ini, tak hanya 1 frame saja yang diletakan dibagian belakang namun disisipkan juga objek tambahan yang diletak di belakang serta depan (foreground) frame. Background dalam film ini menggunakan outline dengan proses pewarnaan yang simpel sehingga dapat cepat dalam proses pembuatannya.

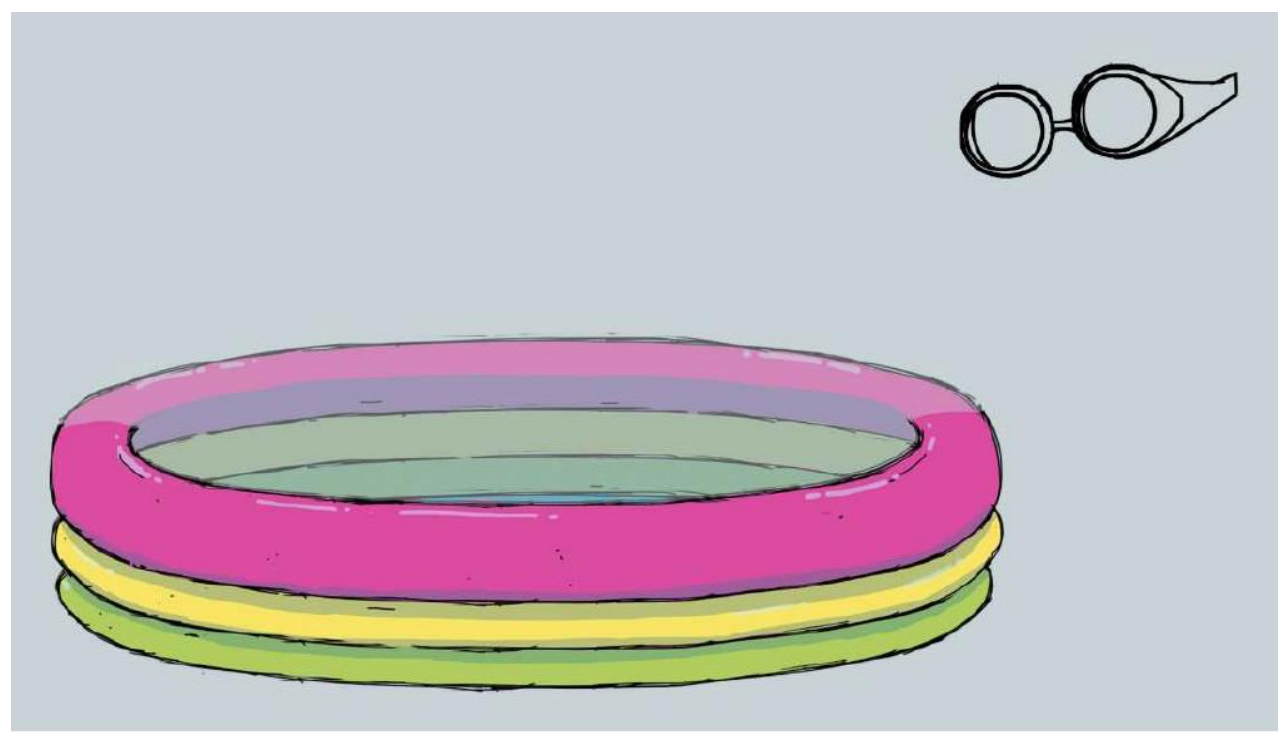

Gambar 5 Salah satu aset background

Gambar 5 merupakan aset yang digunakan pada film "Pool." Dalam proses background pembuatan aset juga faktor yang dapat digunakan berkali-kali tanpa harus mengulangi lagi disetiap shot nya.

Proses pembentukan ulang karakter dilakukan sehingga lebih jelas dan benar sesuai standar karakter yang ada. Proses ini disebut proses layout. Gambar di atas 
adalah salah satu layout yang sudah dibuat dengan menyesuaikan desain karakter yang ada dan background yang sudah dibuat pada shot itu.

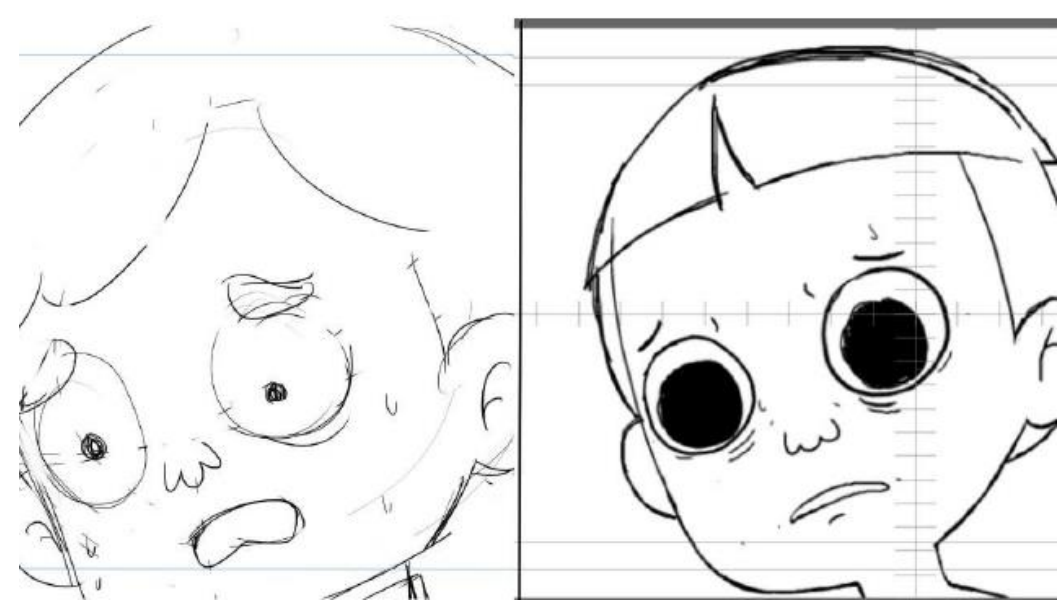

Gambar 6 Salah satu bagian dari proses layout

Pengerjaan keypose dan inbetween mengacu pada seberapa banyak dibutuhkannya suatu adegan yang diperlukan dalam satu shot. Setiap shot yang ada ini sudah ada durasi dan layout sehingga pembuatan keypose akan lebih mudah. Perangkat lunak animasi yang di gunakan untuk proses animate ini menggunakan software TV Paint.

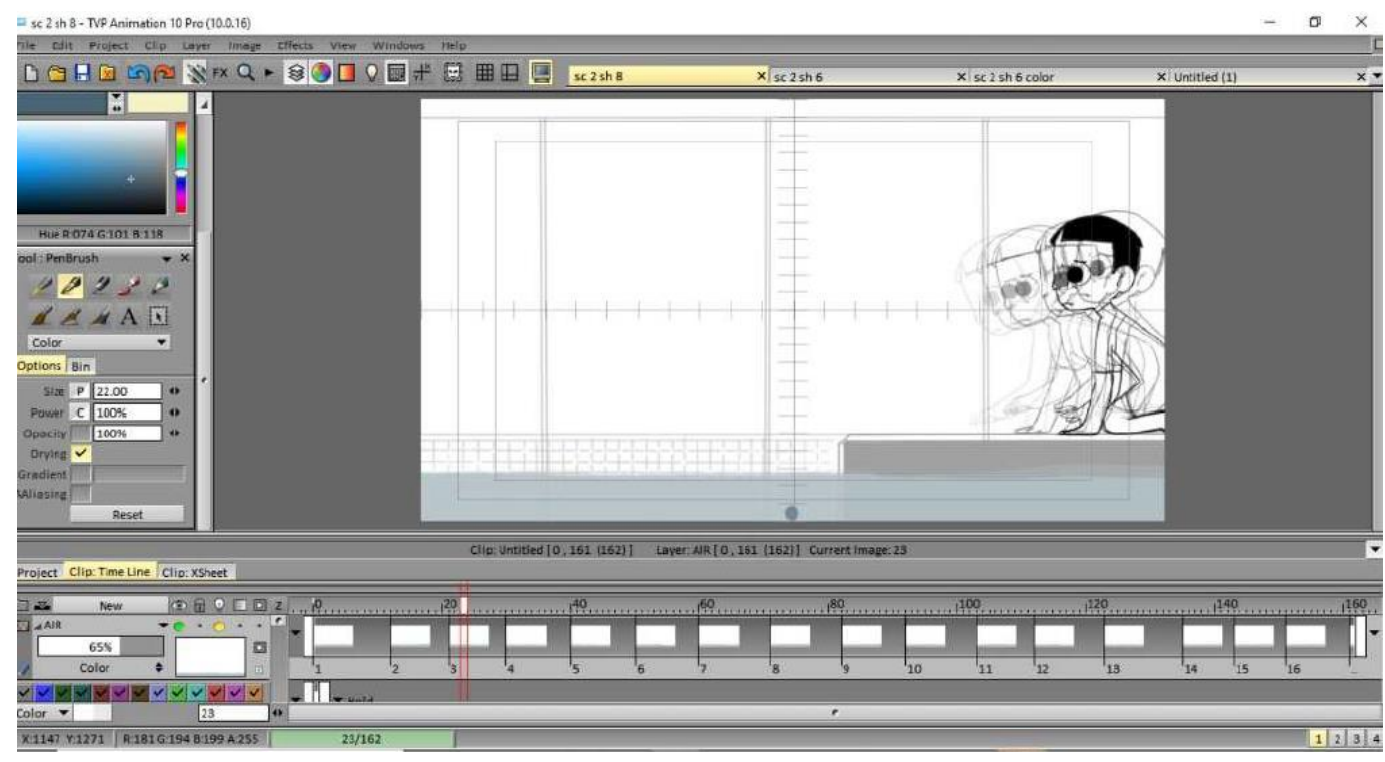

Gambar 7 tangkapan layar keypose dan inbetween shot 8

Dalam pengerjaannya, proses keypose pada satu shot memakan waktu 3-4 jam, lalu 23 jam pembuatan inbetween, dan 1-2 jam clean up. Thomas dan Johnston mencetuskan 
12 prinsip animasi yang diadopsi dari produksi animasi Disney. Mereka menjelaskan 12 prinsip animasi yang perlu diterapkan agar sebuah animasi menjadi tampak lebih hidup, natural, dramatis dan menarik (Thomas \& Johnston, 1995, hal. 211). Dalam karya animasi ini, 12 prinsip animasi juga diterapkan.

Proses pewarnaan pada film ini menggunakan software TV Paint, dengan proses blocked color tanpa shading. Color pallete sangat penting dalam proses ini karna akan menjadi patokan dari shot awal sampai akhir. Berikut contoh coloring untuk shot 6 pada film "Pool".

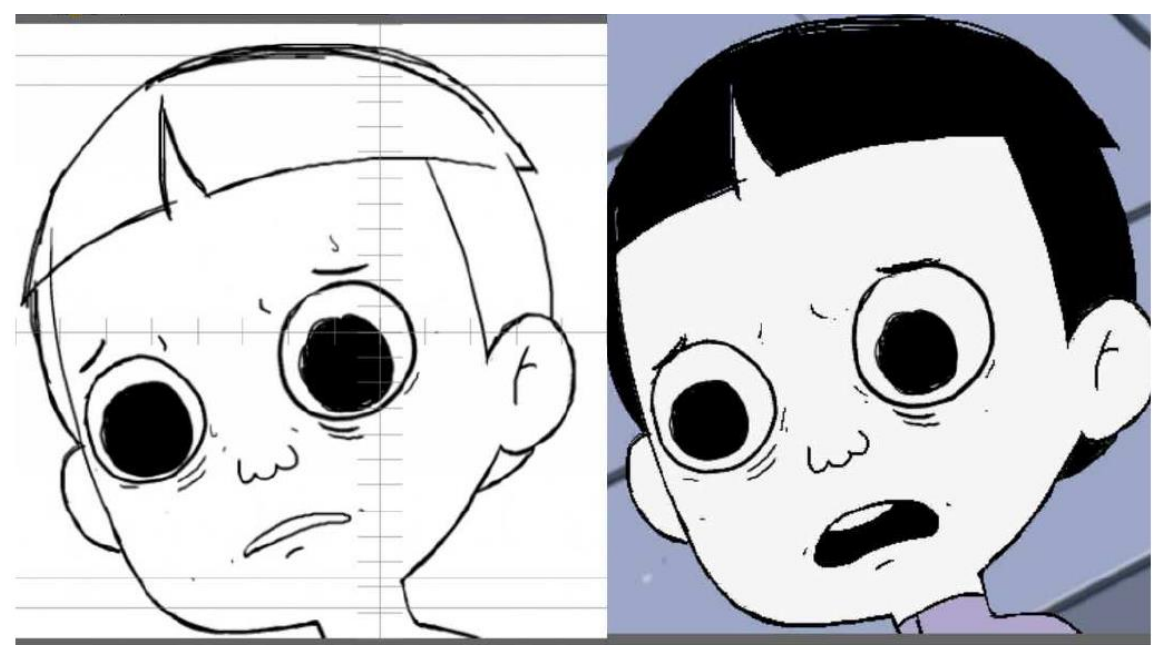

Gambar 8 Proses coloring 


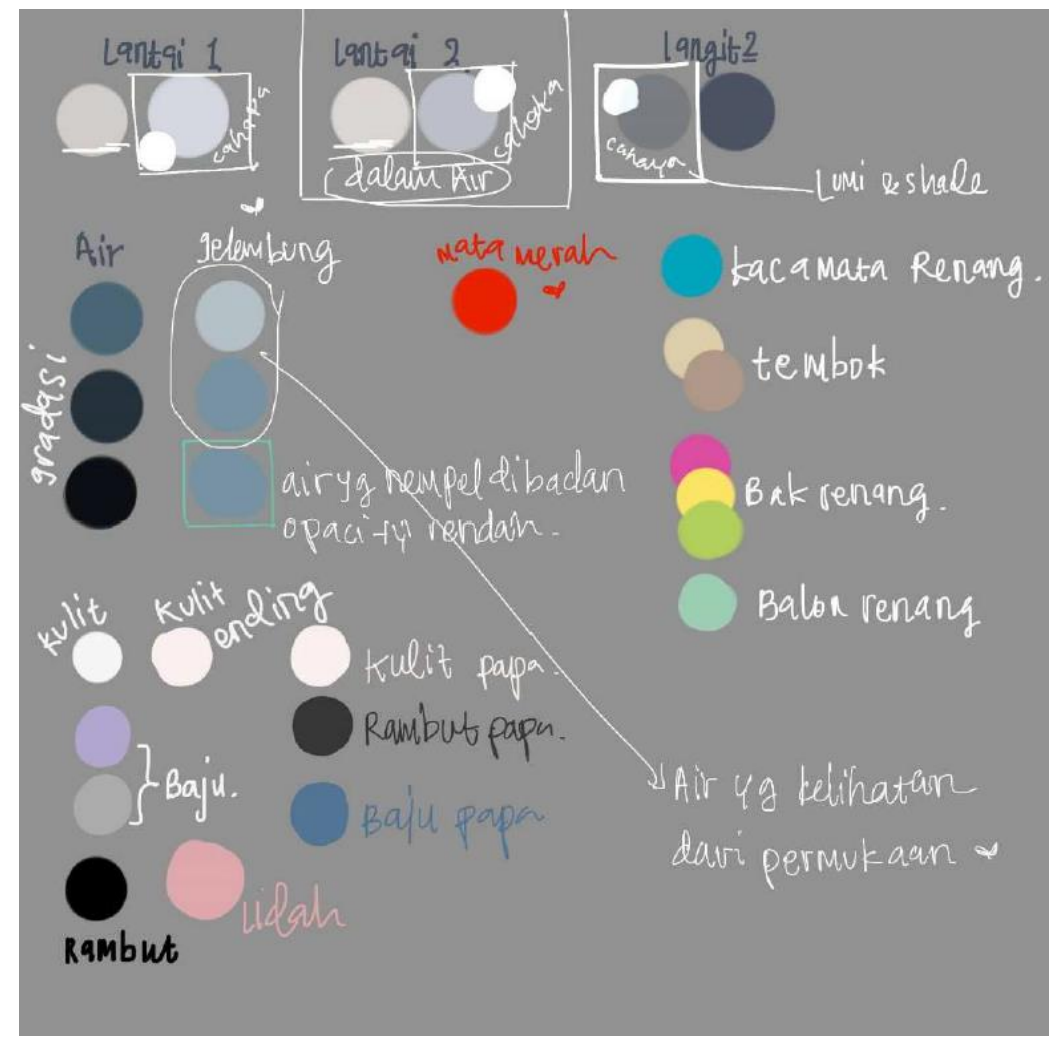

Gambar 9 color pallete yang digunakan dalam film animasi Pool

Gambar 9 merupakan color pallete yang digunakan untuk Proses penyesuaian dengan warna background sehingga menghindari warna yang kontras dan berbeda saat composite.

\section{Kesimpulan}

Karya tugas akhir film animasi 2D "Pool" mengisahkan momen masa lampau dan keadaan yang harus dihadapi oleh Boy sekarang ini hingga ia memiliki harapan untuk kedepannya. Didampingi oleh Papa yang ada bersamanya, Boy tidak merasa sendirian lagi. Film bernuansa horror ini memberi pesan bahwa suatu kecelakaan kecil yang berawal dari kejahilan orang lain dapat memberikan dampak yang berbeda dengan orang yang berbeda pula. Dengan dukungan orang yang menyayangi kita dan juga yang kita sayang, kita tidak akan merasa sendirian lagi saat sedang ketakutan.

Hasil akhir karya film animasi 2D "Pool" sudah cukup mendekati karya referensi yang menjadi tinjauan. Latar belakang dan aset yang digunakan, dalam film animasi "Pool" adalah sebagian besar di kolam renang, dan terakhir di halaman. 
Background di bawah merupakan awal terjadinya kejadian buruk bermula bersama satu teman yang tidak diketahui namanya. Penggunaan warna yang kebanyakan biru mampu membangkitkan kesan mencekam sesuai dengan nuansa yang dibuat dalam film ini.

Riset yang mendalam dengan sejumlah referensi dalam segala aspek animasi sangat membantu pengembangan dan memperkuat karakteristik pada film animasi 2D "Pool." Disarankan bahwa selalu memastikan film animasi yang dikerjakan menerapkan 12 prinsip animasi serta usahakan membuat daftar pekerjaan yang harus diselesaikan setiap harinya. Timeline kerja, tabel yang berisikan kumpulan shot juga perlu dibuat. Semua ini penting, agar tidak kehilangan arah saat akan mengerjakan.

\section{Referensi}

Fernandez, I. (2002). Macromedia Flash Animation \& Cartooning: A Creative Guide. McGraw Hill/Osborne.

Hall, C. S. (2000). Libido Kekuasaan Sigmund Freud (S. Tasrif (penerj.)). Tarawang. Kaplan, H. I., \& Sadock, B. J. (1997). Diagnosa Keperawatan Pada Keperawatan Psikiatri. PT Refika Aditama.

Thomas, F., \& Johnston, O. (1995). The Illusion of Life: Disney Animation. Disney Editions. https://books.google.co.id/books?id=2x0RAQAAMAAJ 